\title{
Assessment of transport and logistics commerce in agriculture for the Southern Federal District of Russia
}

\author{
Pavel Popov ${ }^{1, *}$, Dmitry Gudkov ${ }^{2}$, and Nadezhda Galtseva ${ }^{3}$ \\ ${ }^{1}$ Volzhsky Branch Volgograd State University, 404132, Volzhsky, Russia \\ ${ }^{2}$ Volgograd State Technical University, 400005, Volgograd, Russia \\ ${ }^{3}$ National Research Moscow State University of Civil Engineering, 129337 Moscow, Russia
}

\begin{abstract}
The scientific paper provides a comparative analysis of the development level of the transport infrastructure in the Russian Federation constituents of the Southern Federal District. The analysis of the statistical data on the transport activity shows an increase in the volume of transport services in Rostov-on-Don and Krasnodar from 2012 to 2018. In Volgograd region and Astrakhan Oblast there is a decrease by $22 \%$ and $6 \%$ respectively. With regard to the motor hard surface highways per $1000 \mathrm{~km}^{2}$ there is a significant difference between the Russian Federation constituents in the Southern Federal District. The gap in the values of indicators in Krasnodar, Rostov-on-Don and other regions reaches $50 \%$. In addition, a direct relationship between the social indicators and the volume of transport services for the period under consideration has been identified. In order to assess the development level of the region's transport and logistics infrastructure an integral indicator has been calculated based on the calculation of the relative coefficients of the transport activity in the Russian Federation constituents. As a result, the study shows that the highest value of the integral indicator characterizing the development level of the vehicular transport infrastructure is in Krasnodar Territory, the lowest value is in the Republic of Kalmykia. It should be noted that there is a significant imbalance in the development level of the transport and logistics infrastructure in different regions, which determines their different investment attractiveness and social and economic progress.
\end{abstract}

\section{Introduction}

Transport infrastructure as the main component of the logistics infrastructure is one of the key drivers contributing to the transition of the Russian economy to an innovative development. The Concept of Social and Economic Development says that in order to achieve a high level of social and economic development it is necessary to create new territorial growth centers by means of eliminating the imbalance in the Russian Federation constituents transportation system and also by enhancing transport accessibility of the territories.

\footnotetext{
* Corresponding author: donpascha@yandex.ru
} 
Transport infrastructure also has a significant impact on the social and economic development of the regions of the countries. In particular, the work by ChaoWang, Yul-Seong Kim and Chi Yeol Kim [1] establishes a cause-and-effect relationship between the logistics infrastructure of China and its economic growth from 2000 to 2017. Based on the linear multiple regression model the authors argue that the transport infrastructure plays a key role in the country's international trade. The influence of the logistics infrastructure on the economic development of the provinces of Spain is analyzed in the scientific work by Pelayo Arbuésa, José F. Bañosa and Matías Mayor [2]. According to the research carried out by the authors, the development of the transportation infrastructure has a positive impact on the economic development of the provinces. In addition, the scientists pay attention to the influence of the logistics infrastructure of one province on the economic development of the adjacent territories. The transport component of the logistics infrastructure also has a significant impact on the foreign direct investment (FDI) promotion. Tilo F. Halaszovicha and Aseem Kinra [3] argue that the amount of FDI and the development level of the national transport infrastructure are inextricably linked. They attribute this to the reduction in transportation expenditures resulting in the decrease in production costs. French and Chinese scientists have a similar opinion [4]. Based on the study carried out by the scientists from 46 countries, it is concluded that there is a relationship between the transport and logistics infrastructure and FDI promotion.

Transport and logistics infrastructure also has a significant impact on the trade. For example, the Trade Development Strategy notes that there is heterogeneity of the trade development in the constituents of the Russian Federation, which, among other things, results from the development disparity of the transport and logistics infrastructure. The studies by the foreign scientists confirm the dependence of the trade development on the logistics infrastructure. On the basis of the gravity model Dilay Çelebi [5] shows that in the countries with low and middle income per capita, the development of the transport infrastructure contributes to a jump in the export, whereas in the countries with high level of income there is an increase in the import. A positive impact of the development of logistics infrastructure on the international trade is shown in the work by Sami Bensassi et al. [6]. The scientists have assessed the relationship between the export of goods from 19 provinces of Spain to 45 countries of the world and the development level of the regional transport network. Based on the gravity model, it has been proven that the capacity and number of the key transport infrastructure facilities have a significant impact on the international trade. The scientists from Dutch university have come to a similar conclusion using meta-analysis and metaregression [7]. Based on 36 infrastructure indicators, the authors have concluded that an increase in the number of transport and logistics facilities in the region by 1 percent leads to an increase in export by about 0.6 percent and in import by 0.3 percent. Similar results were obtained in the work [8]. The authors state that FDI in logistics infrastructure has the greatest impact on the international trade. Work [9] confirms that there is a significant impact of the region's transport infrastructure both on the volume of the international trade and on the transnational supply chains formation.

Thus, the development of the transport component of the logistics infrastructure has a positive impact on the social and economic development of the regions both by minimizing expenditures in the distribution network and the capability to maintain the given level of the customer service. It also helps to eliminate the imbalance in the development level of the transport infrastructure in the constituents of the country.

\section{Methods}

Inequality in the development of the transport infrastructure between the regions of the countries has been the focus of several studies so far. In most works, scientists evaluate the 
level of the infrastructure development of the territories and make comparisons in order to identify imbalances. For example, to assess the level of the logistics infrastructure in Italy, Mazziotta and Vidoli [10] used DEA method. Within the framework of this approach, the expert method identifies the indicators characterizing transport activity, their weight and shows the methodology for calculating the integral indicator of the country's infrastructure functionality. To assess the infrastructural functionality of the Italian regional provinces Bollino, Polinori and Mastromarco, Woitek [10] use the method of stochastic frontier analysis. Resulting from the study, the authors explain the imbalance in the social and economic development of the North and South of Italy by the insufficient functionality of the logistics infrastructure facilities in the southern provinces. Quantitative and expert methods for assessing the competitiveness of territories are also widely used. Recently, foreign scientists have often used the methods based on the calculation of the integral indicators using the data from the World Bank, the Organization for Economic Cooperation and Development, and the Joint Research Center of the European Commission [11].

The purpose of this study is to assess the transport and logistics commerciality of the constituents of the Southern Federal District on the basis of calculating an integral indicator showing the level of the relative coefficients of the transport activity. The development level of the vehicular transport infrastructure is assessed according to the values of the indicators from 2012 to 2018 on the basis of the following method. At the initial stage, the indicators that characterize the activity of the vehicular transportation are determined. Based on the fact that the indicators are presented in different scales, all the variables are reduced to the same scale for measuring z-scores. Further, relative coefficients of the regions are calculated according to the formulas:

$$
K_{1}=\frac{\text { volume of region transportatin services }}{\text { region population }}
$$

where

$K_{l}$ - is the relative coefficient, representing the ratio between the volume of the region transportation services and the region population

$$
K_{2}=\frac{\text { length of motor hard surface highways per } 1000 \mathrm{~km}^{2} \text { of of the region territory }}{\text { region population }}
$$

where

$K_{2}$ - is the region relative coefficient representing the ratio between the length (in $\mathrm{km}$ ) of the motor hard surface highways per $1000 \mathrm{~km}^{2}$ of of the region territory and the region population

$$
K_{3}=\frac{\text { region road haulage volume }}{\text { region population }}
$$

where

$K_{3}$ - is the region relative coefficient representing the ratio between the region road haulage volume and the region population

At the last stage, the integral indicator is calculated for each constituent of the Russian Federation of the Southern Federal District according to the formula (4):

$$
S=\frac{\sqrt{K_{1}^{2}+K_{2}^{2}+K_{3}^{2}}}{\sqrt{3}}
$$

\section{Results}

Today, the process of transferring the logistics services market from the center to the periphery of the country is mainly associated with the active emergence of international and national retail chains in the regions. Logistic servicing of such companies is one of the main 
development factors for the logistics market in the regions of Russia. So, from 2012 to 2018 the part of the transport services volume in the Southern Federal District in Volgograd decreased by $22 \%$, in Rostov-on-Don it increased by $32 \%$, in Astrakhan it decreased by $6 \%$, and in Krasnodar it increased by $51 \%$ ( Fig. 1).
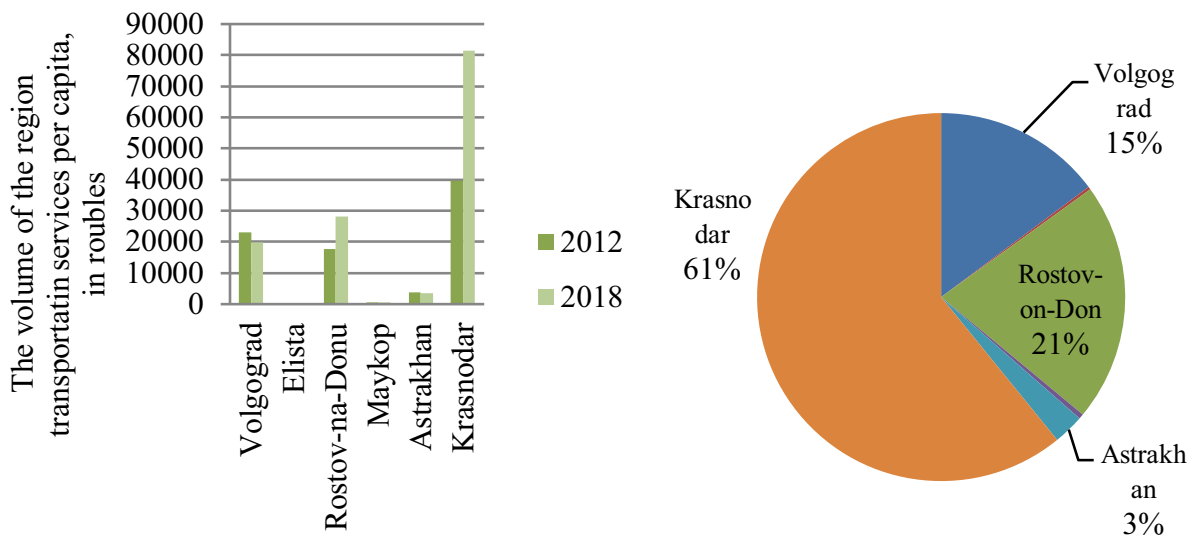

Fig. 1. Distribution of the volume of transport services per capita in the cities of the Southern Federal District.

The transport and logistics infrastructure is characterized by regional disproportionality. The difference of the infrastructure functionality in different cities of the Southern Federal District is about $50 \%$ (Fig. 2).

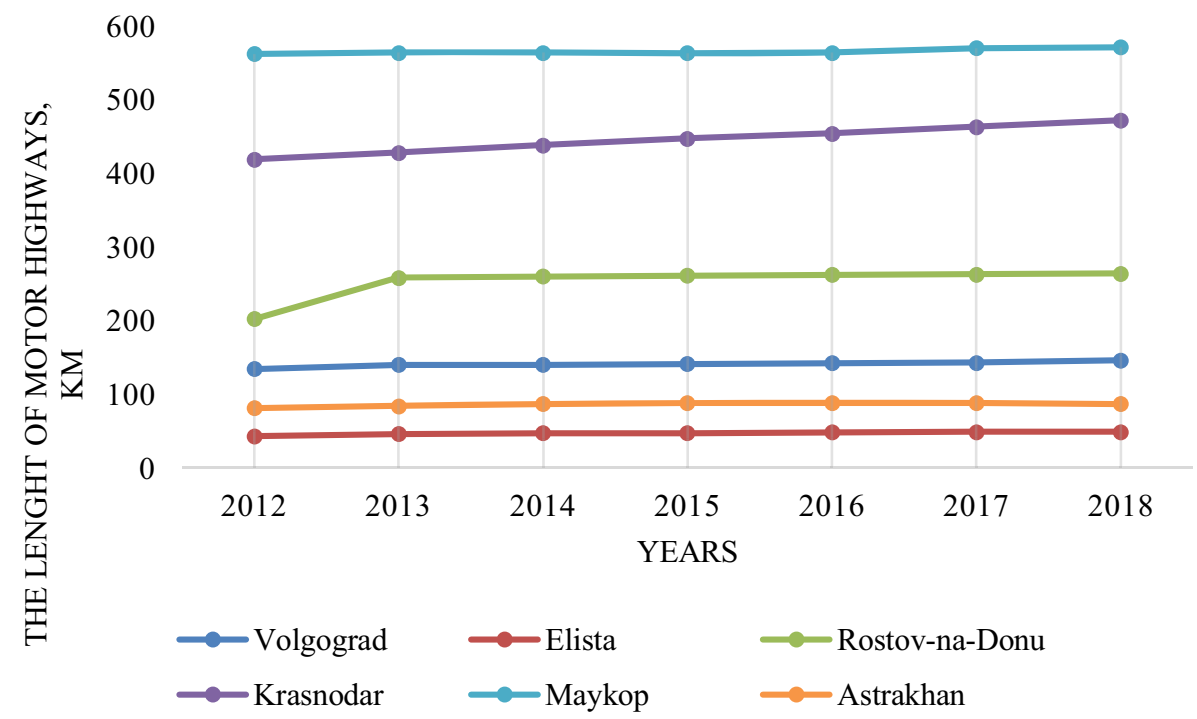

Fig. 2. The dynamics of the length development of the hard-surface roads (in $\mathrm{km}$ ) per $1000 \mathrm{~km}^{2}$ of the territory of the Southern Federal District regions.

The indicators of the demand for truck and warehouse services as well as the assessment of the investment attractiveness of a potential region for the transport and logistics facilities location have a significant impact on the formation of transport and logistics infrastructure.

Resulting from the statistical analysis, the dependence of the volume of transport services on various market factors has been revealed. Thus, the volume of transport services has a 
linear dependence on the volume of the trade and the standard of living of the population (Fig. 3). The largest retail trade turnover from 2012 to 2018 falls on 2018.

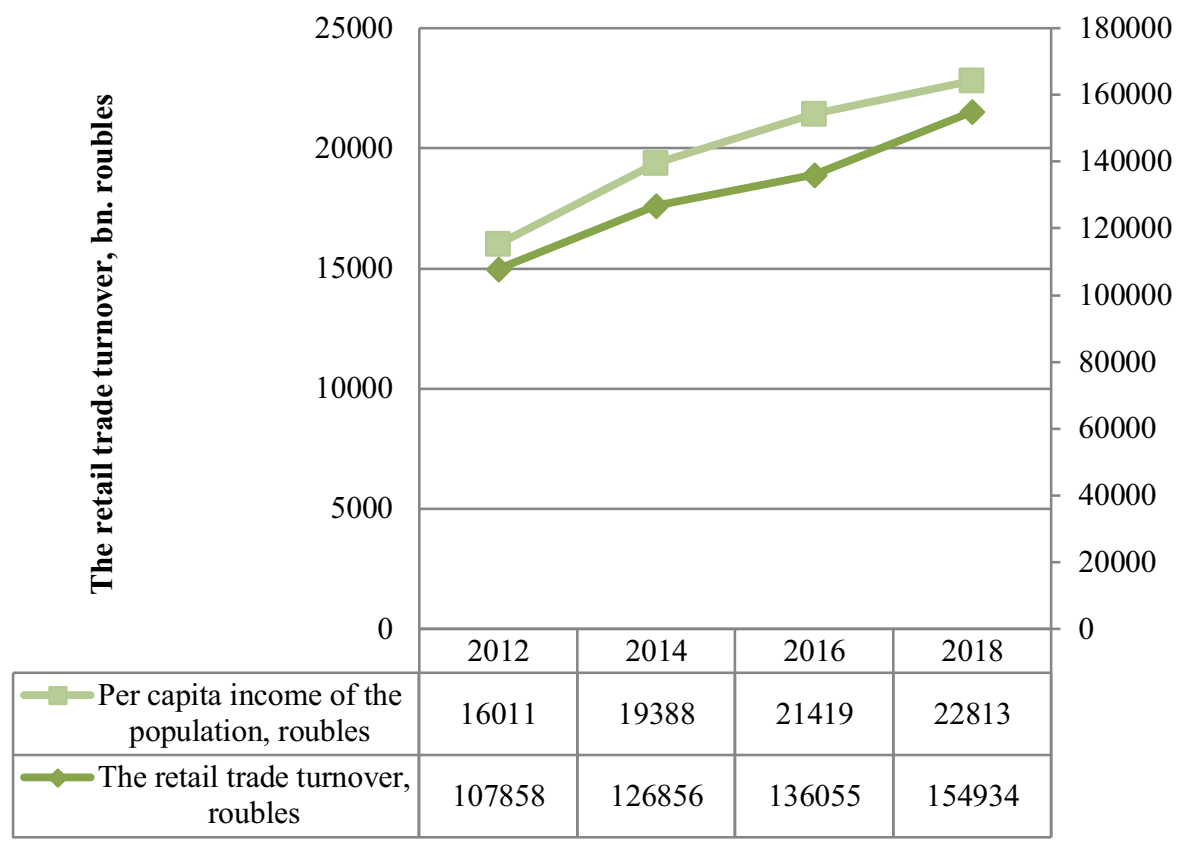

Fig. 3. Dependence of the volume of transport services on the retail trade turnover in Volgograd from 2012 to 2018.

The distribution of the per capita retail trade turnover across the regions is more proportional (Fig. 4). From 2012 to 2018 the share of the average per capita volume in Volgograd decreased from the total turnover of the Southern Federal District from 15 to $14 \%$.

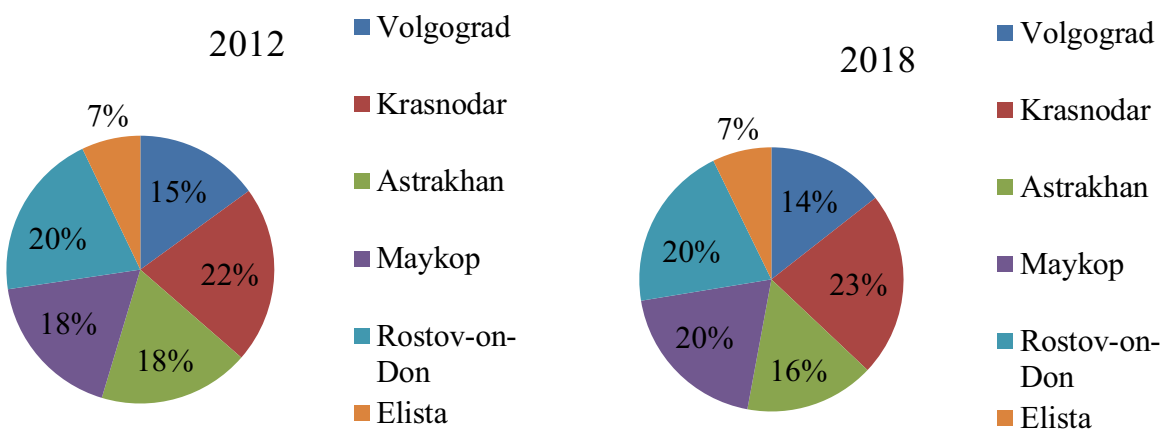

Fig. 4. The share of the Southern Federal District regions in the total retail trade turnover per capita from 2012 to 2018 .

Imported products are delivered to the regions mainly by vehicular transport, hence there is dependence of the volume of the vehicular transportation of goods on the turnover of the trade (Fig. 5). 


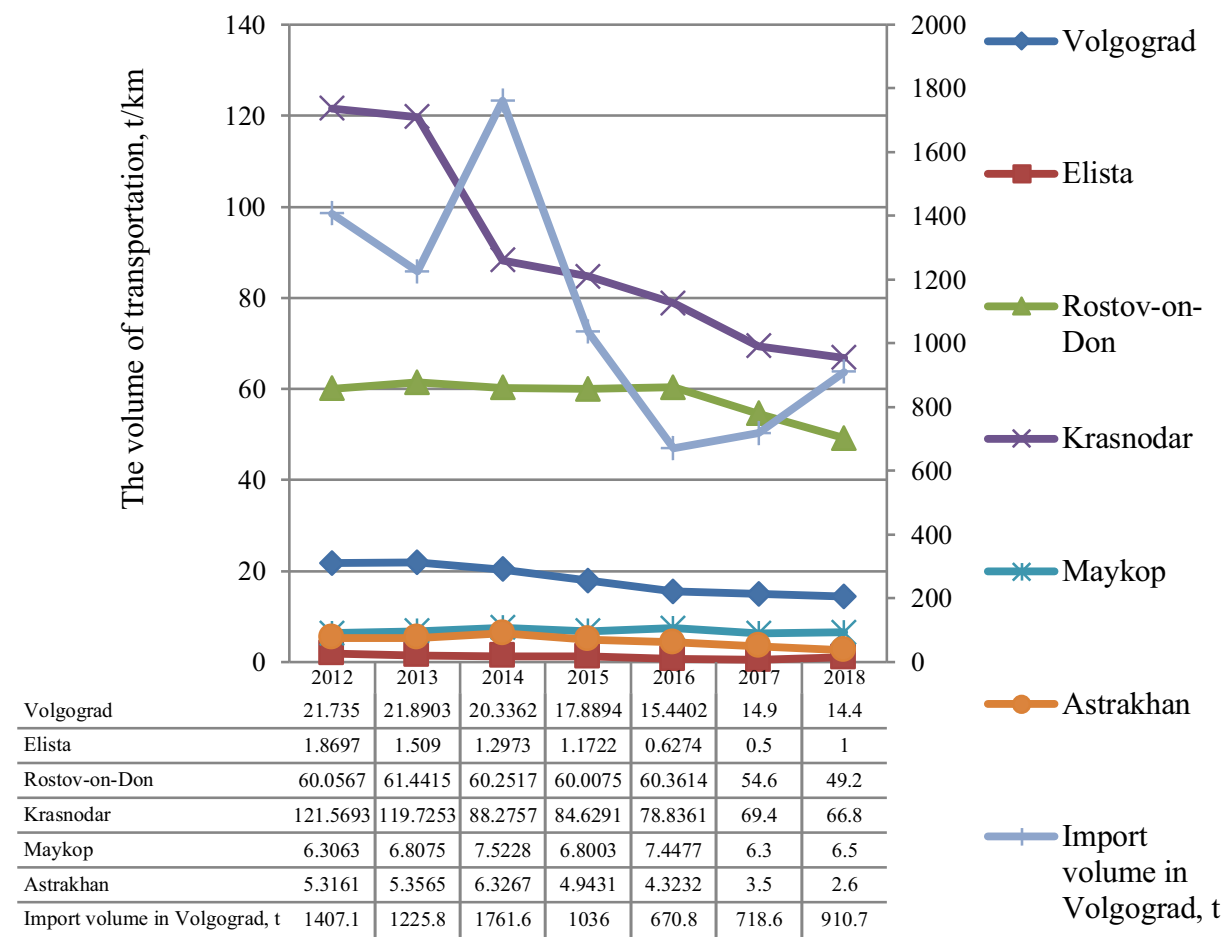

Fig. 5. The volume of vehicular transportation of goods in the cities of the Southern Federal District.

The initial data for calculating the coefficients $K_{l}, K_{2}, K_{3}$ are taken from the official statistical reports on the economic activity in the Southern Federal District regions. As a result of the calculation according to the formulas $1-3$, the values of the relative coefficients for the Southern Federal District constituents have been obtained from 2012 to 2018. (Table 1)

Table 1. Relative coefficients $K_{l}, K_{2}, K_{3}$ of the Russian Federation constituents of the Southern Federal District.

\begin{tabular}{|l|c|c|c|c|c|c|c|}
\hline $\begin{array}{c}\text { Constituen } \\
\text { ts of the } \\
\begin{array}{c}\text { Southern } \\
\text { Federal } \\
\text { District }\end{array}\end{array}$ & $\mathbf{2 0 1 2}$ & $\mathbf{2 0 1 3}$ & $\mathbf{2 0 1 4}$ & $\mathbf{2 0 1 5}$ & $\mathbf{2 0 1 6}$ & $\mathbf{2 0 1 7}$ & $\mathbf{2 0 1 8}$ \\
\hline $\begin{array}{l}\text { Volgograd } \\
\text { Oblast }\end{array}$ & & & & & & & \\
\hline K1 & 0.02266 & 0.01922 & 0.01979 & 0.02039 & 0.01807 & 0.01865 & 0.01953 \\
\hline K2 & 0.00013 & 0.00014 & 0.00014 & 0.00014 & 0.00014 & 0.00014 & 0.00014 \\
\hline K3 & 0.00002 & 0.00002 & 0.00002 & 0.00002 & 0.00002 & 0.00001 & 0.00001 \\
\hline $\begin{array}{l}\text { Republic of } \\
\text { Kalmykia }\end{array}$ & & & & & & & \\
\hline K1 & 0.00282 & 0.00307 & 0.00295 & 0.00298 & 0.00315 & 0.00324 & 0.00328 \\
\hline K2 & 0.00041 & 0.00044 & 0.00045 & 0.00045 & 0.00046 & 0.00047 & 0.00048 \\
\hline K3 & 0.00002 & 0.00001 & 0.00001 & 0.00001 & 0.00001 & 0.000005 & 0.00001 \\
\hline $\begin{array}{l}\text { Rostov } \\
\text { Oblast }\end{array}$ & & & & & & & \\
\hline K1 & 0.016 & 0.018 & 0.019 & 0.020 & 0.022 & 0.023 & 0.025 \\
\hline K2 & 0.0001842 & 0.0002338 & 0.0002343 & 0.0002341 & 0.0002340 & 0.0002337 & 0.0002336 \\
\hline K3 & 0.000055 & 0.000056 & 0.000054 & 0.000054 & 0.000054 & 0.000049 & 0.000044 \\
\hline $\begin{array}{l}\text { Republic of } \\
\text { Adygea }\end{array}$ & & & & & & & \\
\hline
\end{tabular}




\begin{tabular}{|l|c|c|c|c|c|c|c|}
\hline K1 & 0.00375 & 0.00456 & 0.00383 & 0.00409 & 0.00455 & 0.00491 & 0.00409 \\
\hline K2 & 0.00389 & 0.00390 & 0.00390 & 0.00391 & 0.00392 & 0.00398 & 0.00402 \\
\hline K3 & 0.00004 & 0.00005 & 0.00005 & 0.00005 & 0.00005 & 0.00004 & 0.00005 \\
\hline $\begin{array}{l}\text { Astrakhan } \\
\text { Oblast }\end{array}$ & & & & & & & \\
\hline K1 & 0.007 & 0.006 & 0.006 & 0.006 & 0.006 & 0.006 & 0.007 \\
\hline K2 & 0.00015 & 0.00016 & 0.00016 & 0.00017 & 0.00017 & 0.00017 & 0.00016 \\
\hline K3 & 0.0000101 & 0.0000102 & 0.0000119 & 0.0000093 & 0.0000081 & 0.0000066 & 0.0000049 \\
\hline $\begin{array}{l}\text { Krasnodar } \\
\text { Oblast }\end{array}$ & & & & & & & \\
\hline K1 & 0.052 & 0.067 & 0.076 & 0.079 & 0.082 & 0.088 & 0.091 \\
\hline K2 & 0.001 & 0.001 & 0.001 & 0.001 & 0.001 & 0.001 & 0.001 \\
\hline K3 & 0.000159 & 0.000153 & 0.000110 & 0.000102 & 0.000092 & 0.000079 & 0.000074 \\
\hline
\end{tabular}

In some cases, the values of the relative coefficients differ by tens of times for various constituents. For example, the relative coefficient $K_{l}$ for the Volgograd Oblast differs from the value of $K_{l}$ for the Astrakhan Oblast by 4.8 times. This shows a significant disproportional development of the Southern Federal District constituents in the field of transport infrastructure. Despite the differences, the decrease in the value of the relative coefficients has been observed since 2014 practically in all the series. This is largely due to the decline in the economic activity after the imposition of restrictive measures by a number of states against Russia.

The value of the integral indicator for each constituent of the Russian Federation is presented in Table 2.

Table 2. Integral indicator of the development level of the vehicular transport infrastructure of the Russian Federation constituents in the Southern Federal District.

\begin{tabular}{|l|c|c|c|c|c|c|c|}
\hline & $\mathbf{2 0 1 2}$ & $\mathbf{2 0 1 3}$ & $\mathbf{2 0 1 4}$ & $\mathbf{2 0 1 5}$ & $\mathbf{2 0 1 6}$ & $\mathbf{2 0 1 7}$ & $\mathbf{2 0 1 8}$ \\
\hline $\begin{array}{l}\text { Volgograd } \\
\text { Oblast }\end{array}$ & 0.01308 & 0.0111 & 0.01142 & 0,01177 & 0.01043 & 0.01077 & 0.01128 \\
\hline $\begin{array}{l}\text { Republic of } \\
\text { Kalmykia }\end{array}$ & 0.00165 & 0.00179 & 0.00172 & 0,00174 & 0.00184 & 0.00189 & 0.00191 \\
\hline Rostov Oblast & 0.00934 & 0.01022 & 0.01102 & 0,01181 & 0.01254 & 0.01338 & 0.01435 \\
\hline $\begin{array}{l}\text { Republic of } \\
\text { Adygea }\end{array}$ & 0.00312 & 0.00346 & 0.00316 & 0,00327 & 0.00346 & 0.00365 & 0.00331 \\
\hline Astrakhan Oblast & 0.0042 & 0.00329 & 0.00362 & 0,00357 & 0.00372 & 0.00373 & 0.00389 \\
\hline Krasnodar Oblast & 0.0300 & 0.03865 & 0.04402 & 0,04552 & 0.04729 & 0.0509 & 0.05229 \\
\hline
\end{tabular}

\section{Conclusion}

The analysis of the results obtained shows the multidirectional dynamics of the level of development of the vehicular transport infrastructure of the Southern Federal District regions. In particular, the Volgograd Oblast and Astrakhan Oblast show negative dynamics resulted from the decrease of the investment in transport infrastructure and general stagnation of business. However, over the past two years, there has been an increase in the integral indicator for the Volgograd Oblast, which is due to the direct public and private investments in the road infrastructure as a result of the decision to host several matches of the World Cup in Volgograd. The highest level of the development of the vehicular transport infrastructure and the highest growth rate of the integral indicator for the period under review are in the Krasnodar Territory, which is associated with the implementation of the large infrastructure projects for the Olympic Games. It should also be noted that there is a significant difference in the values of these indicators, which shows a significant imbalance in the level of transport functionality of the regions and as a result in their social and economic development. In order to reduce the disproportional development of the regions, it is necessary to implement 
infrastructure projects within the framework of the national projects and through private investment promotion.

\section{References}

1. C. Wang, Y.-S. Kim, C.Y. Kim, Transport Policy 100, 49-58 (2021) DOI: 10.1016/j.tranpol.2020.10.005

2. P. Arbués, J.F. Baños, M. Mayor, Transportation Research Part A: Policy and Practice 75, 166-177 (2015) DOI: 10.1016/j.tra.2015.03.010

3. T.F. Halaszovich, A. Kinra, Transport Policy 98, 35-47 (2020) DOI: 10.1016/j.tranpol.2018.09.003

4. S. Saidi, V. Mani, H. Mefteh, M. Shahbaz, P. Akhtar, Transportation Research Part A: Policy and Practice 141, 277-293 (2020) DOI: 10.1016/j.tra.2020.09.020

5. D. Çelebi, Maritime Economics \& Logistics 21, 307-323 (2019) DOI: 10.1057/s41278017-0094-4

6. S. Bensassi, L. Márquez-Ramos, I. Martínez-Zarzoso, C. Suárez-Burguet, Transportation Research Part A: Policy and Practice 72, 47-61 (2015) DOI: 10.1016/j.tra.2014.11.007

7. G. Celbis, P. Nijkamp, J. Poot, REGION 1(1), 25-64 (2015) DOI: 10.18335/region.v1i1.25

8. A. Gani, The Asian Journal of Shipping and Logistics 33, 279-288 (2017) DOI: 10.1016/j.ajsl.2017.12.012

9. S. Park, Transport Policy 99, 54-62 (2020) DOI: 10.1016/j.tranpol.2020.07.016

10. F. Carlucci, A.Cirà, E. Forte, L. Siviero, Technological and Economic Development of Economy 23(2), 243-269 (2017) DOI:10.3846/20294913.2015.1070768

11. P. Annoni, K. Kosovska, EU regional competitiveness index 2010. Joint Research Centre European Commission (Publication Office of the European Union, Luxemburg, 2010) 